\title{
Decentralized Automated Dispensing Devices: Systematic Review of Clinical and Economic Impacts in Hospitals
}

\author{
Nicole W Tsao, Clifford Lo, Michele Babich, Kieran Shah, and Nick J Bansback
}

\begin{abstract}
Background: Technologies have been developed over the past 20 years to automate the stages of drug distribution in hospitals, including ordering, dispensing, delivery, and administration of medications, in attempts to decrease medication error rates. Decentralized automated dispensing devices (ADDs) represent one such technology that is being adopted by hospitals across Canada, but the touted benefits, in terms of improved patient safety and cost savings, are increasingly being questioned.
\end{abstract}

Objective: To summarize and evaluate the existing literature reporting the clinical and economic impacts of using decentralized ADDs in hospitals.

Data Sources: A literature search was conducted in MEDLINE, Embase, and all evidence-based medicine databases for the years 1992 to 2012 to identify English-language articles reporting on the use of ADDs in hospital wards.

Study Selection and Data Extraction: All randomized controlled trials, observational studies, before-and-after studies, time series analyses, cost-effectiveness and cost-benefit analyses, and review articles were considered for inclusion. Studies evaluating pharmacy-based ADDs, such as bar code-based medication dispensing carousels, automated dispensing shelves, and combinations of various dispensing modalities, were excluded.

Data Synthesis: Of 175 studies initially identified, 8 were retained for evidence synthesis. It appears that ADDs were effective in reducing medication storage errors and the time that nurses spent taking inventory of narcotics and controlled substances. There was no definitive evidence that using $\mathrm{ADDs}$ increased the time that nurses or pharmacists spent with patients, reduced medication errors resulting in patient harm, or reduced costs in Canadian hospitals. However, pharmacy technicians spent more time stocking the machines.

Conclusion: ADDs have limited potential to decrease medication errors and increase efficiencies, but their impact is highly institution-specific, and use of this technology requires proper integration into an institution's medication distribution process. Before deploying this technology, it is recommended that Canadian hospitals carefully examine their current systems and the benefits they hope to gain with the changes.

Keywords: automated dispensing device, medication errors, costs

\section{RÉSUMÉ}

Contexte : Au cours des vingt dernières années, des technologies ont été développées afin d'automatiser les étapes de la distribution des médicaments dans les hôpitaux, notamment pour ce qui est de l'émission d'ordonnances et de la dispensation, de la délivrance et de l'administration des médicaments, le tout dans le but de réduire le nombre d'erreurs de médication. Les cabinets automatisés décentralisés (CAD) font partie de ces technologies qui sont adoptées par les hôpitaux du Canada, mais leurs bienfaits très publicisés, en ce qui a trait à l'amélioration de la sécurité des patients et aux économies pouvant être réalisées, sont de plus en plus remis en question.

Objectif : Résumer et évaluer la littérature faisant état des retombées cliniques et économiques de l'utilisation de CAD dans les hôpitaux.

Sources des données : Une recherche documentaire a été effectuée dans MEDLINE, Embase ainsi que dans l'ensemble des bases de données médicales fondées sur des preuves pour la période allant de 1992 à 2012 afin de trouver les articles rédigés en anglais qui font état de l'utilisation des CAD dans les services d'hôpitaux.

Sélection des études et extraction des données : Cette revue a pris en considération toutes les études cliniques aléatoires, les études observationnelles, les études avant-après, les analyses de séries chronologiques, les analyses coût-avantage et coût-efficacité, et les articles de synthèse. Les études évaluant les CAD en usage dans les pharmacies, robots parmi lesquels on compte les carrousels de distribution de médicaments utilisant des codes-barres, les rayonnages de distribution automatisés et les combinaisons de différents moyens de distribution, n'ont pas été retenues.

Synthèse des données : Des 175 études d'abord recensées, huit ont été retenues pour la synthèse des données probantes. Les CAD semblent avoir été utiles pour réduire le nombre d'erreurs d'entreposage de médicaments ainsi que le temps nécessaire au personnel infirmier pour faire l'inventaire des narcotiques et des substances contrôlées. Aucune donnée probante ne permet d'affirmer que le temps passé par le personnel infirmier et les pharmaciens auprès des patients a augmenté, que le nombre d'erreurs de médication causant du tort aux patients a baissé ou que les coûts des hôpitaux canadiens ont chuté grâce à l'utilisation des CAD. Par contre, les techniciens en pharmacie ont passé plus de temps à remplir les machines.

Conclusion : Les CAD présentent un faible potentiel de réduction du nombre d'erreurs de médication et d'augmentation de l'efficacité des ressources. Cependant, leur incidence est propre à chaque établissement 
Can J Hosp Pharm. 2014;67(2):138-48 et l'utilisation de cette technologie nécessite une intégration réfléchie dans le processus de distribution des médicaments d'un établissement. Avant de mettre en place cette technologie, il est recommandé aux hôpitaux canadiens de bien étudier leurs systèmes actuels et de réfléchir aux avantages qu'ils espèrent obtenir par ce changement.

Mots clés : cabinet automatisé décentralisé, erreurs de médication, coûts

[Traduction par l'éditeur]

\section{INTRODUCTION}

Since the Institute of Medicine published To Err is Human in $1999,{ }^{1}$ health care institutions have recognized the need to make systemic changes and find innovative solutions to improve quality related to patient safety. Yet more than a decade later, preventable medication-related errors continue to be a major cause of morbidity and mortality in Canada. In 2011, Hohl and others ${ }^{2}$ estimated that the Canadian burden associated with in-hospital adverse drug events was more than 1.5 million hospital days, leading to hospitalization costs of $\$ 2.2$ billion to $\$ 5.6$ billion annually (in 2008 Canadian dollars).

With the desire to improve quality, the pressure to reduce costs, and the pharmacy profession's transition to direct patient care, pharmacy departments have looked to automation to expand their distribution capabilities and to improve efficiency. One such technology that is increasingly being used in Canadian hospitals is referred to by various terms, including automated dispensing cabinets and automated dispensing devices (ADDs). Recent surveys have indicated that by 2009/2010, ADDs were being used in at least 53\% of Canadian hospitals (Hospital Pharmacy in Canada survey) ${ }^{3}$ and $89 \%$ of US hospitals (American Society of Health-System Pharmacists survey). ${ }^{4}$

The higher uptake of ADDs in the United States has not necessarily been the result of a drive for safer systems. They were initially employed in US hospitals to help capture all patient-specific financial charges, to ensure that a complete bill would be available on discharge, and to track narcotics and controlled substances in response to a federal monitoring system. ${ }^{5}$ Given that these benefits cannot be realized in the Canadian setting, it is unclear whether the uptake of expensive technology such as ADDs in Canadian hospitals (by $47 \%$ between 2007/2008 and 2009/2010) was cost-effective. ${ }^{3}$

A systematic review of technologies intended to reduce errors in dispensing and administration of medications in hospitals, published by the Canadian Agency for Drugs and Technology in Health in 2009, showed that implementation of a hospital ward-based (decentralized) ADD could reduce costs and error rates in medical and surgical patient care units but would increase costs in intensive care units (ICUs). ${ }^{6}$ Detailed review of this report indicates that this conclusion was driven largely by unpublished data (cited as "Baker 2008") from Cardinal Health, which at the time owned Pyxis, a pioneer and manufacturer of ADD technology. ${ }^{6}$

The objective of the current systematic review was to facilitate evidenced-based decision-making regarding the use of ADDs in Canadian hospitals by providing an unbiased assessment of the clinical and economic impacts of using decentralized ADDs relative to traditional, centralized processes for manual dispensing of medications.

\section{METHODS}

\section{Literature Search}

A literature search for the period 1992 to 2012 was conducted within MEDLINE (1946 to present with daily update), Embase (1974 to 2012 week 26), the Cochrane Database of Systematic Reviews (2005 to May 2012), ACP Journal Club (1991 to June 2012), the Database of Abstracts of Reviews of Effects (second quarter 2012), Cochrane Central Register of Controlled Trials (June 2012), Health Technology Assessment (second quarter 2012), and National Health Service Economic Evaluation Database (second quarter 2012) with the following search terms: "automated dispensing device", "automated dispensing cabinet", "automated dispensing machine", "automated dispensing system", "drug distribution system", "Pyxis", "Omnicell”, and "Medstation" (see Appendix 1 for MEDLINE search strategy). The search was limited to English-language articles because the authors did not have the resources to translate or interpret publications in other languages. The reference lists of relevant articles identified by these searches were reviewed manually for additional studies.

\section{Inclusion Criteria}

Articles reporting on the use of ward-based (i.e., decentralized) ADDs, including all published randomized controlled trials, observational studies (cohort and case-control), beforeand-after studies, time series analyses, cost-effectiveness or cost-benefit analyses, and review articles, were considered for inclusion. Unpublished studies were not considered, as these 


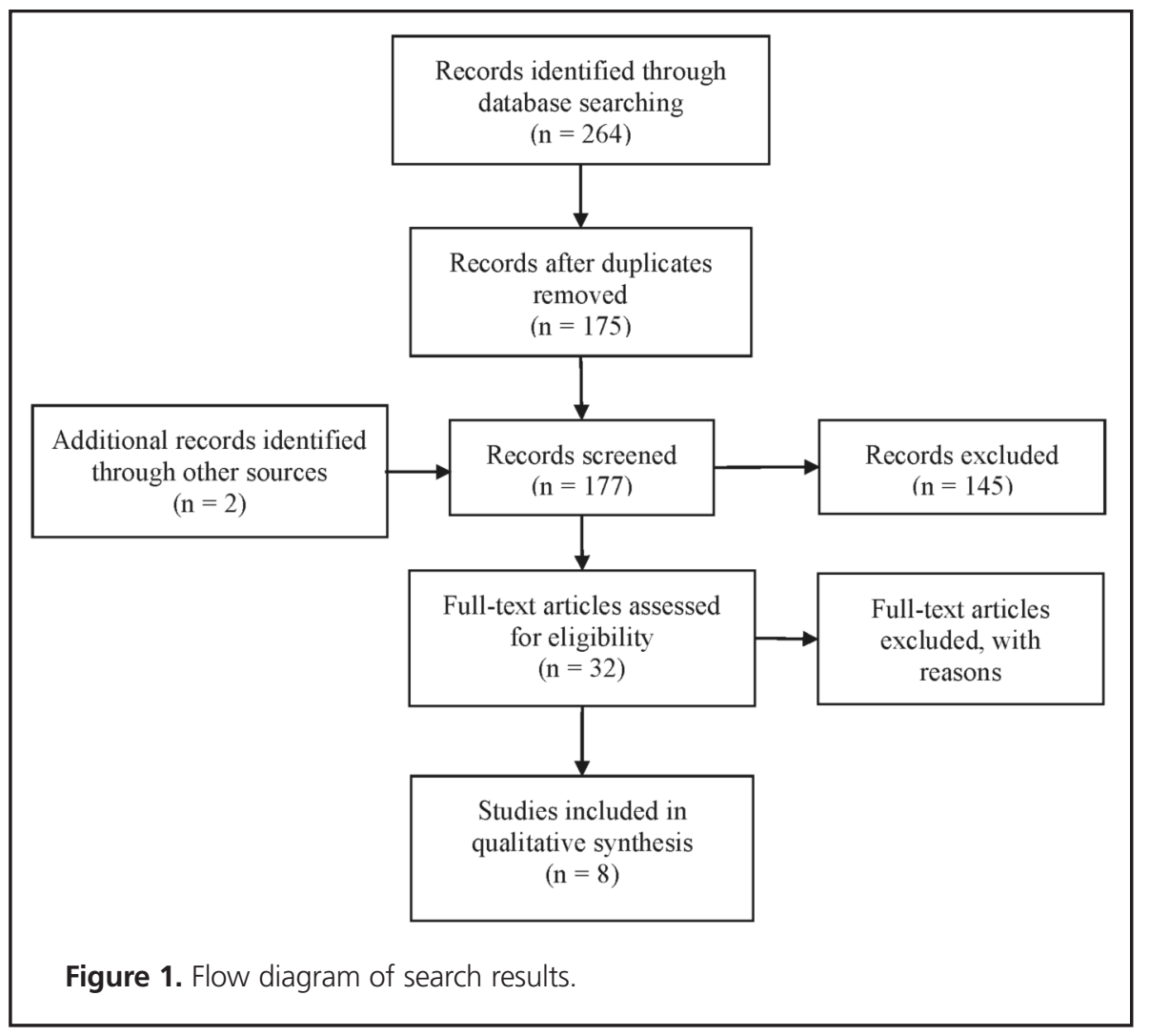

have not undergone peer review or review of any kind. Studies must have investigated and reported on one or more of the following outcomes of interest: medication error rates, efficiency (time, staffing, workload, etc.), or costs.

\section{Exclusion Criteria}

Because the objective of this analysis was to evaluate the benefit of ward-based ADDs relative to traditional manual medication-dispensing processes (including centralized unit-dose systems), studies evaluating pharmacy-based ADDs, such as bar code-based medication dispensing carousels, automated dispensing shelves, and combinations of various automated dispensing modalities, were excluded. Studies comparing one type of ADD with another were excluded, as were those evaluating the same ADD implemented on different hospital wards.

\section{Analysis}

Two reviewers (N.W.T., C.L.) independently screened all relevant abstracts and full-text articles for inclusion, resolving any disagreements by discussion. For each full-text study included in the analysis, the same 2 reviewers independently extracted data for the following variables: title, authors, and year of publication; study type; sample size; inclusion and exclusion criteria; interventions; outcomes; and results. Results were categorized according to the outcomes of interest (medication error rates, efficiency, and cost). We were unable to contact the authors of any of the studies for additional data. All included studies were critically appraised for internal validity and generalizability; any issues affecting the results are considered in the Discussion section, below.

\section{RESULTS}

A total of 175 unique records were identified, of which 145 were excluded at the abstract review stage (Figure 1). Two studies identified through manual searching of other articles' reference lists were included for full-text review. In total, 32 full-text articles were reviewed, 24 of which were subsequently excluded. Therefore, a total of 8 studies were included for evidence synthesis: 6 prospective before-and-after studies, 1 time flow study, and 1 randomized controlled trial (RCT). Characteristics of the included studies are summarized in Table 1. ${ }^{714} \mathrm{ADD}$ s had been implemented in ICUs, general medicine wards, surgical units, or a combination of these locations within the study hospitals. All studies were conducted in the United States, except for one study that was performed in France. The duration of the studies ranged from 14 days to 9 months, and all were published between 1992 and 2010.

\section{Medication Error Rates}

Five of the 8 included studies examined differences in medication error rates, albeit with various approaches and 
For permission to reprint multiple copies or to order presentation-ready copies for distribution, contact CJHP at cjhpedit@cshp.ca

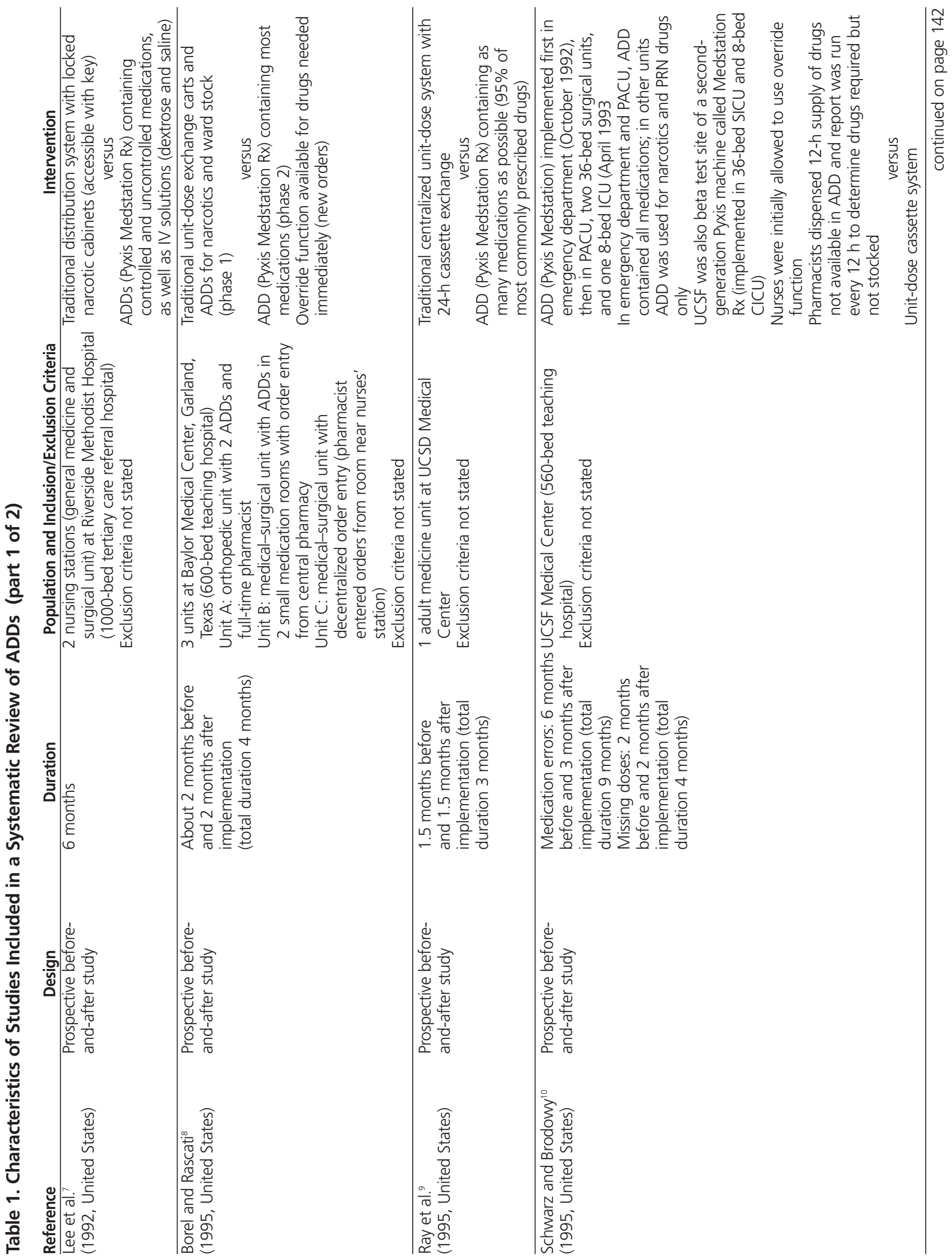


For permission to reprint multiple copies or to order presentation-ready copies for distribution, contact CJHP at cjhpedit@cshp.ca

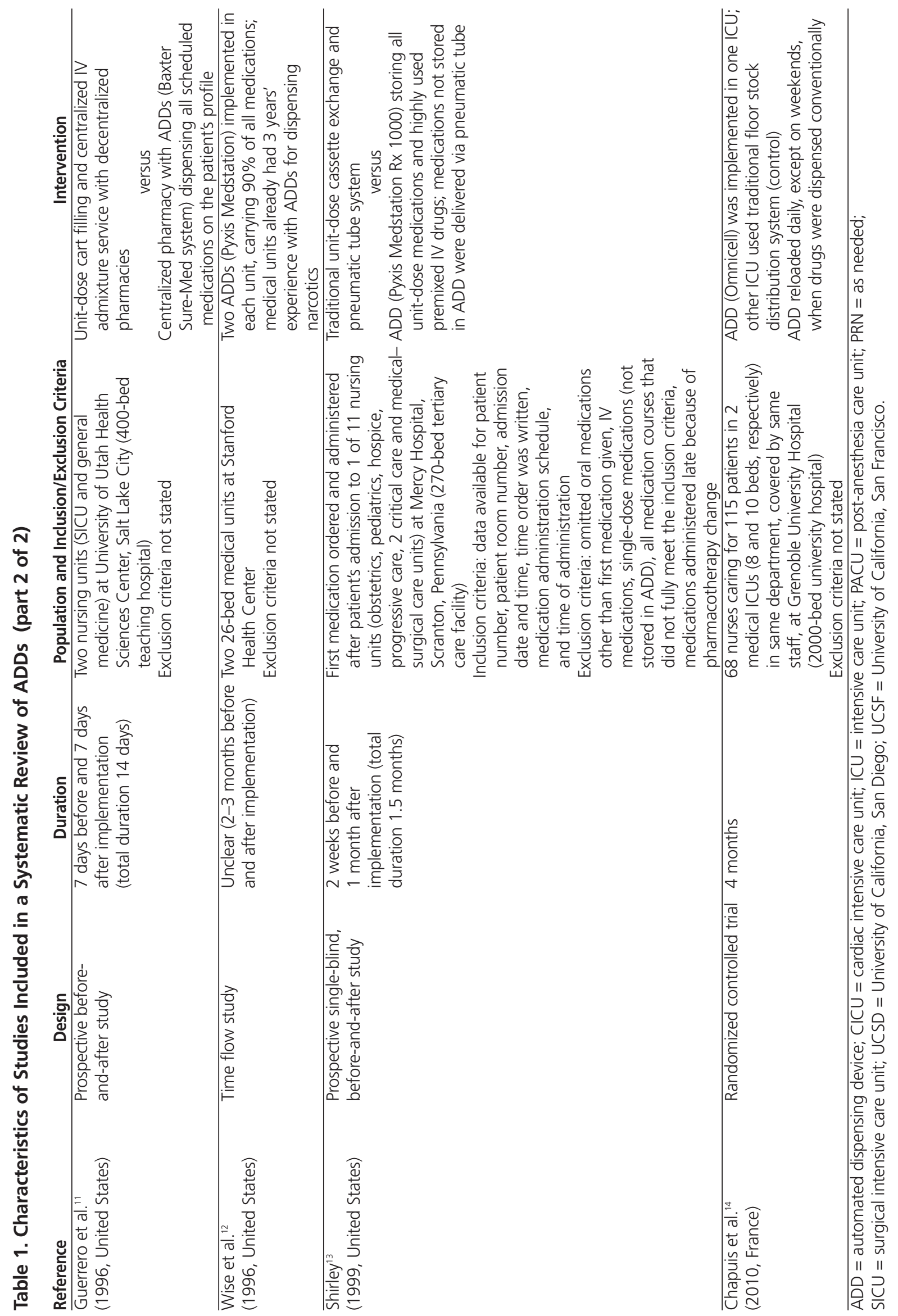


definitions. ${ }^{8,9,10,13,14}$ Four of these studies employed a prospective before-and-after design, whereby data were collected for a specified period before and after ADD implementation. ${ }^{8,9,10,13}$ The fifth study was a 4-month RCT reporting the impact of ADDs on medication error rates at a university hospital in France. $^{14}$ This was the only study comparing error rates of ADDs with error rates for a traditional floor stock drug distribution system. All other studies took place at hospitals that used unit-dose cassette systems.

Borel and Rascati ${ }^{8}$ conducted a prospective before-andafter study at a teaching hospital in Garland, Texas. They implemented ADDs in 3 units of the hospital and compared ADDs with the existing unit-dose cassette system via direct observation. Observers watched nurses enter data on the ADD screens and remove the medication doses; observers also verified whether the correct drug was selected for the correct patient and whether the drug was given. Observers also checked the medication administration records (MARs) to verify that the correct dose was given and recorded the time of administration. Omission errors were recorded if examination of the MAR revealed that a prescribed drug had been missed. The overall error rate, defined as the number of errors divided by the number of observations, was reduced following implementation of the ADDs, from $17.0 \%$ (148/873) to $10.4 \%$ (97/929) $(p=0.001)$. This reduction was driven by a $73 \%$ relative reduction in omission errors, from $4.1 \%$ (36/873) to $1.1 \%(10 / 929)$. However, it is not known whether errors classified as omission errors actually represented delayed doses, with the medication being given at a time when the nurses were not being observed. Wrong-time errors were most prevalent, at 10.4\% (91/873) before and 8.4\% (78/929) after ADD implementation. Mean deviations from scheduled medication administration times were $34.5 \mathrm{~min}$ (standard deviation [SD] $48.9 \mathrm{~min}$ ) before and $30.1 \mathrm{~min}(\mathrm{SD} 31.6 \mathrm{~min}$ ) after ADD implementation $(p=0.03)$. Little difference was found for errors related to wrong dose, wrong dosage form, unauthorized drug, wrong route, wrong rate, wrong preparation, or extra doses.

Ray and others ${ }^{9}$ conducted the only study examining error rates for stocking of medications by pharmacy technicians before and after implementation of ADDs at a medical centre in San Diego, California. For 6 weeks before conversion to ADDs, pharmacists checked unit-dose cassettes after technicians had filled them and recorded the number of errors found. Then, for 6 weeks after ADD implementation, pharmacists similarly checked medications in the ADDs after technicians had stocked them and recorded the number of errors found. Error rates, in terms of percentage of doses dispensed, were significantly lower with ADDs than with unit-dose cassettes (0.61\% versus $0.89 \%, p=0.04)$.

Schwarz and Brodowy ${ }^{10}$ studied the impact of implementing ADDs in a surgical ICU and a cardiac ICU at the University of
California, San Francisco Medical Center, relative to unit-dose cassette systems. They analyzed the type and frequency of medication errors from incident reports for 6 months before and 3 months after ADD implementation. They found that the mean number of errors per month decreased in the surgical ICU, from 6.5 (SD 2.6) before to 4.3 (SD 2.3) after ADD implementation, but increased in the cardiac ICU, from 1.0 (SD 1.3) to 1.7 (SD 0.6). Schwarz and Brodowy ${ }^{10}$ noted that their results were not interpretable because of data contamination introduced by a new pilot error-reporting form, which increased medication errors by $30 \%$ in 7 nursing units (including the surgical and cardiac ICUs). They did find that ADDs were associated with a reduction in the mean rate of missing doses, from 13.8/day (SD 7.1) to 3.3/day (SD 3.4) in the surgical ICU and from 33.8/day (SD 3.0) to 1.2/day (SD 1.5) in the cardiac ICU ( $p<0.05$ for both).

Shirley ${ }^{13}$ investigated 11 nursing units in a tertiary care hospital in Pennsylvania that switched from unit-dose cassette systems to ADDs. Data were collected on medication administration time for the first orally administered medication after each patient's admission to a nursing unit. The author found that after ADD implementation, the proportion of medications administered on schedule increased from $59 \%$ to $77 \%$. Mean deviation between scheduled and actual medication administration times improved from $129.84 \mathrm{~min}$ to $101 \mathrm{~min}$, but this change was not statistically significant $(p=0.157)$. In an attempt to conduct a single-blind study, the author obtained actual medication administration times from a chart review, not by direct observation.

Chapuis and others ${ }^{14}$ conducted a 4-month RCT involving implementation of an ADD in one ICU and usual practice (traditional floor stock drug distribution system) in another ICU (control) within the same department of a 2000-bed university hospital. The primary outcome of this study was total error rate, defined as percent total opportunities for error (calculated by dividing the number of drugs associated with one or more errors by the number of drugs ordered). Secondary outcomes included percent of detailed opportunities for error and percent of storage errors. Detailed opportunities for errors were defined as any gesture or action by a nurse that could result in the following types of errors: (1) picking errors (wrong name, dosage, or pharmaceutical form); (2) preparation errors (wrong dose, solvent type, or volume for reconstitution, or wrong mixtures); (3) administration errors (wrong technique, route, rate, or administration time more than $1 \mathrm{~h}$ before or $1 \mathrm{~h}$ after the expected time; physicochemical incompatibility); (4) omissions; and (5) extra doses. These authors found that total error rates differed significantly between the control and study units after implementation of the $\mathrm{ADD}$ (18.6\% versus $13.5 \%$, $p<0.05)$, whereas no difference was found before ADD implementation. Total error rates in the intervention unit were 
$20.4 \%$ before and $13.5 \%$ after implementation $(p<0.01)$, a decrease of 6.9 percentage points (compared with a decrease of 0.7 percentage points in the control unit). Wrong-dose errors declined from $3.8 \%$ to $0.5 \%$ ( $p=0.017$ ); however, no difference was found in picking and administration errors, including wrong-time errors, omission errors, or extra doses given. There were $14.4 \%$ fewer storage errors in the study unit than in the control unit $(p<0.01)$.

\section{Efficiency}

Five of the 8 studies investigated the impact of ADDs on various efficiency outcomes. ${ }^{7,910-12}$ Most of the studies looked at differences in the time that pharmacists, pharmacy technicians, and nurses spent performing medication-related activities. The methods of measurement were relatively consistent among the studies, with all but one study collecting data by direct observation of time spent on defined activities by various personnel.

\section{Nurses' Time}

Implementing ADDs for narcotics and controlled substances clearly resulted in a reduction in nurses' time for certain activities. For example, Schwarz and Brodowy ${ }^{10}$ found that implementation of $\mathrm{ADDs}$ reduced the mean time that nurses spent on acquisition of a single narcotic dose from $107 \mathrm{~s}$ (SD $106 \mathrm{~s})$ to $48 \mathrm{~s}$ (SD $23 \mathrm{~s}$ ). Time spent taking inventory of controlled substances also decreased, from $5.04 \mathrm{~h} /$ week to $0.36 \mathrm{~h} /$ week. $^{10}$ However, the results were less clear with respect to all other medications. Lee and others ${ }^{7}$ documented the time that nurses spent on various activities before and after ADD implementation, specifically medication-related activities (including preparation of medications stored as floor stock, controlled substances, unit-dose medications, and IV admixtures); charting or documentation; interaction with patients; interaction with other personnel; and miscellaneous activities. After implementation of ADDs, the proportion of nurses' time spent on medication-related activities decreased from $10.2 \%$ to $5.6 \%(p<0.05)$ and time spent on charting or documentation decreased from $28.0 \%$ to $16.9 \%$ ( $p<0.05) .^{7}$ Conversely, time spent on interaction with patients increased from $20.0 \%$ to $28.6 \%(p<0.05)$. There was no change in time spent interacting with other personnel (20.5\% versus $22.5 \%)$. The results of 2 other studies ${ }^{11,12}$ were conflicting. Wise and others ${ }^{12}$ observed that nurses' time required to gather medications increased by an average of $2.3 \mathrm{~min} /$ day, with this increase being offset by a decrease in medication administration time of $6.7 \mathrm{~min} /$ day. They also found that nurses' total travel time during a shift was reduced from $20.2 \mathrm{~min}$ to $6.34 \mathrm{~min}$ as a result of ADD implementation. However, in a self-report work sampling study, Guerrero and others ${ }^{11}$ found that ADDs had no impact on the time that nurses spent performing medication-related activities.

\section{Pharmacy Technicians' Time}

In the study by Lee and others, ${ }^{7}$ the time that pharmacy technicians spent stocking all medications other than narcotics increased significantly after ADD implementation, from a mean of $7.17 \mathrm{~min}$ (SD $1.63 \mathrm{~min}$ ) to a mean of $48.96 \mathrm{~min}$ (SD $8.77 \mathrm{~min}$ ) per nursing unit. However, there was no change in the time required to stock narcotic drugs. Wise and others ${ }^{12}$ found that $\mathrm{ADD}$ implementation resulted in an average increase of $5 \mathrm{~min} /$ day in the time required for technicians to fill the ADDs. Any post-implementation efficiencies for technicians' time were related to time spent on billing. Lee and others ${ }^{7}$ reported a decrease in time spent on billing for controlled substances, from a mean of $7.15 \mathrm{~min}(\mathrm{SD} 6.97 \mathrm{~min}$ ) to a mean of $1.36 \mathrm{~min}$ (SD $0.64 \mathrm{~min}$ ). Schwarz and Brodowy ${ }^{10}$ corroborated this result, reporting that ADDs completely eliminated time spent on billing by pharmacy technicians (reductions of $13 \mathrm{~min}$ [SD $16.1 \mathrm{~min}$ ] in the surgical ICU and $8.6 \mathrm{~min}$ [SD $2.2 \mathrm{~min}]$ in the cardiac ICU).

\section{Pharmacists' Time}

Three studies examined changes in time that pharmacists spent on various activities after ADD implementation. Wise and others ${ }^{12}$ found a reduction of $40 \mathrm{~min} /$ day in pharmacists' time required to check unit-dose cassettes or ADDs. Guerrero and others ${ }^{11}$ reported no change in pharmacists' time spent performing distribution activities that, by law, only a pharmacist can do; however, they observed an increase in time spent on clinical activities because of a reduction in time spent on technical functions. Ray and others ${ }^{9}$ reported that a year before ADD implementation, $25 \%$ of clinical pharmacists' time was spent resolving drug distribution problems, whereas 3 years after implementation, this activity occupied only $5 \%$ of their time.

Ray and others, ${ }^{9}$ whose study was sponsored by an $\mathrm{ADD}$ vendor, described a separate study in which they found that the average waiting time for the first dose of a new medication declined from $45 \mathrm{~min}$ with the traditional system to $1 \mathrm{~min}$ with the ADD; in addition, the number of phone calls to the pharmacy was reduced by $90 \%$. However, Ray and others ${ }^{9}$ provided no details as to how the study was conducted or whether the data were reliable.

\section{Costs}

All 3 of the studies that examined "cost-effectiveness" or cost offsets after $\mathrm{ADD}$ implementation reported positive results $^{7,10,12}$ It appeared that increases in charge capture rates and overall decreases in personnel time were the factors primarily responsible for cost offsets in implementing ADDs. Improved charge capture allows the hospital to bill for a larger proportion of medications used, thus increasing revenues. 
Lee and others found that $\mathrm{ADD}$ implementation increased the mean charge capture rate from $63 \%$ to $97 \%$ for floor stock medications, IV solutions, and IV sets in patient care units. These authors estimated that an additional $\$ 250000$ annually would be generated as a result of the ADDs; when the costs of implementation, maintenance, and technician time (total of about $\$ 215000$ annually) were taken into account, a net of $\$ 35000$ was expected (in 1992 US dollars). Schwarz and Brodowy ${ }^{10}$ determined that the economic benefits of ADDs over unit-dose cassette systems stemmed from the ability of $\mathrm{ADDs}$ to reduce overall personnel time. They estimated reductions of 0.8 pharmacist full-time equivalents (FTEs), 2.6 pharmacy technician FTEs, 1.2 pharmacy billing technician FTEs, and 3.0 nurse FTEs, for a total savings of $\$ 2.08$ million over 5 years (1994 US dollars). Wise and others ${ }^{12}$ estimated that a net gain of $230 \mathrm{~h} /$ year of nurses' time attributable to ADDs would generate cost savings of $\$ 8053 /$ year (1994 US dollars). The per-shift reduction in total travel time for nurses equated to savings of $\$ 25471$ year, and the reduction of pharmacists' time equated to savings of $\$ 8807 /$ year. ${ }^{12}$ Along with the increase in charge capture rates, these authors concluded that an annual net saving of \$80910 could be realized, after the rental costs of ADDs (about $\$ 27780$ annually) were taken into account. ${ }^{12}$

\section{DISCUSSION}

To the authors' knowledge, this is the first systematic literature review to summarize the clinical and economic evidence comparing decentralized ADDs with traditional manual medication dispensing processes in the hospital setting. Because of heterogeneity in study designs and outcomes reported, it was not possible to perform a quantitative synthesis of the evidence. Also, many of the studies employed a before-andafter design with direct observation of time that personnel spent on various activities (work sampling), but this type of design has potential biases, such as the Hawthorne effect, ${ }^{15}$ the extent of which could not be ascertained.

Table 2 summarizes the overall impact of ADDs on medication errors. In particular, ADDs were effective in reducing storage errors. Pharmacy technician's errors in filling the ADDs were also reduced relative to errors in filling automated unit-dose cassettes. ${ }^{914}$ However, this outcome is highly institution-specific; for example, it may depend on the number and types of medications that an institution decides to store in the $\mathrm{ADDs}$ or on the drug distribution process used at the institution before ADD implementation. Furthermore, Chapuis and others ${ }^{14}$ were the only authors who assessed the severity of medication errors observed. They found no difference in errors causing harm or death, although this finding was likely due to a sample size that was insufficient to reject the null hypothesis. ${ }^{14}$

The ability of ADDs to reduce nurses' time with respect to distribution of narcotics and controlled drugs was evident and generally accepted. However, results were inconclusive with respect to other medications. Lee and others ${ }^{7}$ and Schwarz and Brodowy ${ }^{10}$ reported that nurses' time was reduced; Wise and others $^{12}$ found that time to gather medications was offset by decreased time for medication administration; and Guerrero and others ${ }^{11}$ found no changes. It remains unclear why ADDs would have any effect on the time taken by nurses for medication administration. Additionally, the number of ADDs implemented in each ward would directly affect nurses' time; ideally, enough machines should be installed to avoid a bottleneck in the overall workflow. Pharmacists' time spent performing technical distribution activities was decreased, while time spent in clinical work appeared to increase, though the strength of this evidence was questionable, with little detail being reported about the magnitude and statistical significance of these differences. ${ }^{911,12}$ In addition, the potential benefit of this observation may no longer be applicable in today's practice setting and the future, as the scope of practice for pharmacy technicians continues to increase.

$\mathrm{ADDs}$ were very effective in increasing charge capture rates and decreasing the time that pharmacy technicians spent on billing. ${ }^{712}$ As such, this technology was reported to be cost-effective or cost-saving. It appears that ADDs increase the accuracy of tracking inventory levels and medication usage per patient, which allows hospitals to accurately bill patients or payers for reimbursement. ${ }^{16}$ This particular aspect of the hospital system does not exist in the Canadian setting, and these economic findings are therefore not generalizable to Canadian hospitals. In a recent systematic review, CADTH looked at all automation technologies intended to reduce errors in dispensing and administration of medications in hospitals. ${ }^{6}$ Except for the inclusion of unpublished data from one ADD vendor, the clinical and cost outcomes in the CADTH review were taken from studies included in the current review and were used to inform an economic model with 2008 Canadian prices applied. ${ }^{6}$ In its base-case analysis, CADTH determined that ADDs in medical and surgical units resulted in cost savings of $\$ 128000$ to $\$ 152000$ over 5 years, whereas ADDs in ICUs led to cost increases ranging from $\$ 76000$ to $\$ 100000$ over 5 years. ${ }^{6}$ According to this analysis, the cost savings associated with ADDs were driven largely by reductions in nurses' and pharmacists' time. Because ICUs had fewer patients taking fewer medications, the scale of cost savings from reduced personnel time were not enough to offset the costs of implementation, planning, and equipment related to the ADDs. ${ }^{6}$ $\mathrm{CADTH}$ made an effort to extrapolate evidence from the literature to the Canadian setting; however, lack of reliable data remained a caveat. ${ }^{6}$ Because the current study included only published, peer-reviewed literature, we were unable to confirm the data that CADTH used in its economic analysis.

The current study had a few limitations. We were unable to assess publication bias in the literature, as most of the studies 
For permission to reprint multiple copies or to order presentation-ready copies for distribution, contact CJHP at cjhpedit@cshp.ca

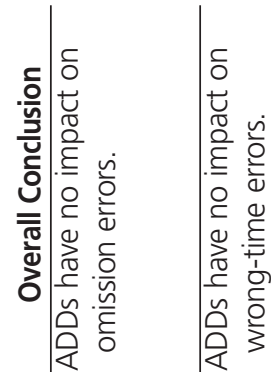

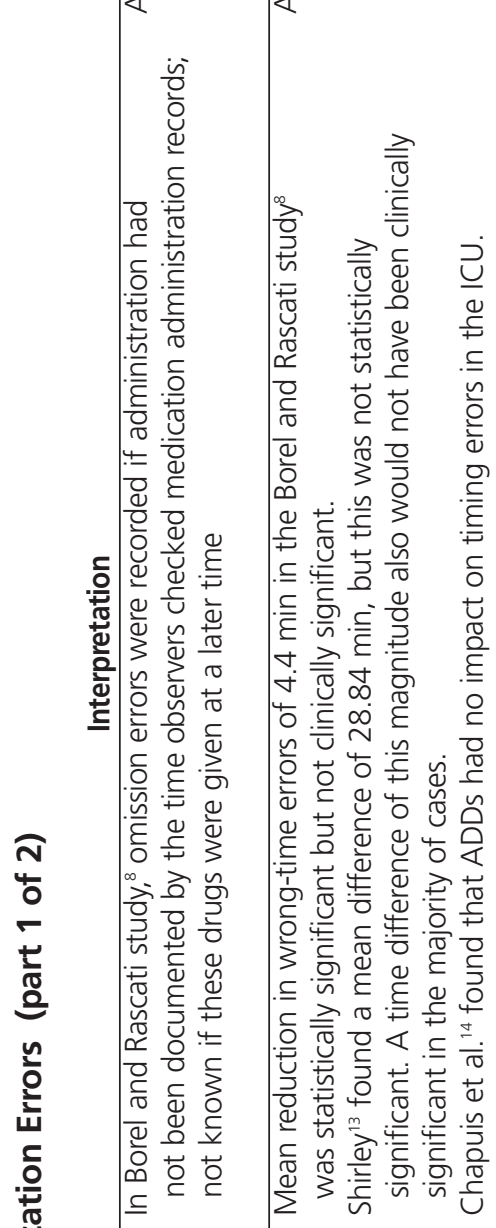

$\frac{.0}{8}$

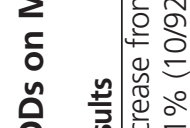

ह

일 2

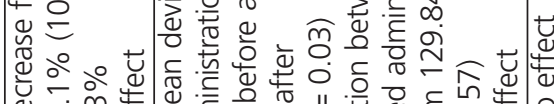

Q

廿 흥

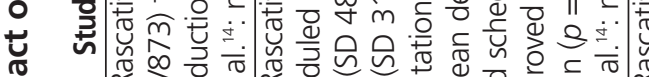

西

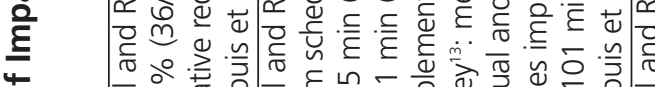

范

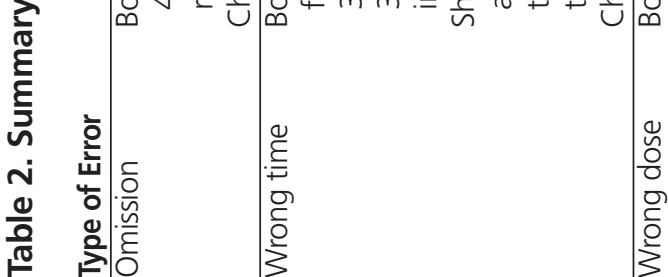

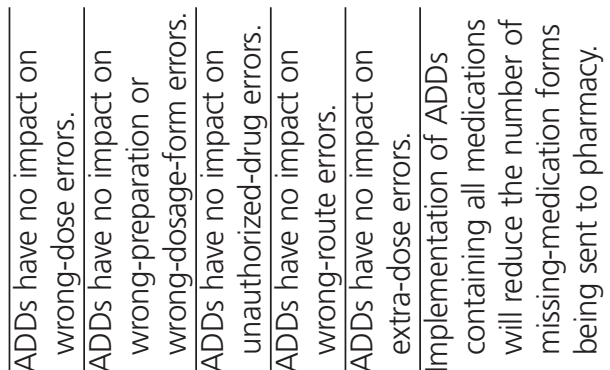

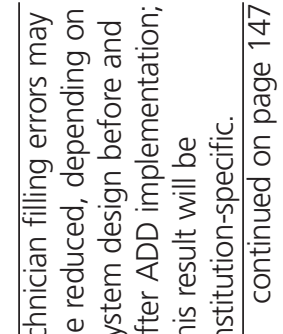

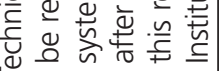

$+$

$\underset{\pi}{\pi}$

華

证

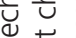

든

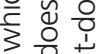

ह थิ

눈

으 $\cong$ 元

는

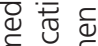

产

ॠ ह 용

世虫

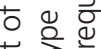

ปิ

চ

ฮิ ติ

을 은 으

잉

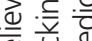

ฮै ญ

ते जे

ᄃ

Ч 屯

원 
pertaining to the research question were small, unregistered observational studies. In addition, no studies were excluded on the basis of quality. Because only 8 publications were relevant to the research question and most were published in the 1990s, excluding studies because of quality would have rendered insufficient data for evidence synthesis. Nevertheless, studies of new technologies rarely involve randomized controlled trials but are usually observational, akin to the majority of studies included in this review. Finally, we were unable to contact the authors of included studies for clarification or additional data. Nevertheless, the literature search was thorough and robust, and detailed data were extracted from each study and then synthesized to arrive at the most appropriate conclusions.

\section{CONCLUSION}

This review has shown that ADDs have the potential to decrease storage errors and pharmacy technician filling errors, while increasing the amount of time that technicians spend on stocking activities. The ability of ADDs to reduce nurses' time spent on distribution of narcotics and controlled drugs was evident and generally accepted. However, results were inconclusive with respect to other medications. There was no definitive evidence that ADDs increased the time that nurses or pharmacists spent with patients, reduced medication errors resulting in patient harm, or reduced costs in Canadian hospitals. Before deploying this technology, it is recommended that Canadian hospitals carefully examine their current systems and the benefits they hope to gain with the change. ${ }^{17}$ Until evidence exists, hospitals must make institution-specific decisions on how to properly configure and integrate ADDs into their workflow. ${ }^{5,17}$ With the rapid uptake of $\mathrm{ADD}$, this area requires additional study, since the improper management of ADDs is believed to jeopardize patient safety. ${ }^{5,17}$ Also, more longitudinal studies are required to capture less common medication errors causing patient harm or death. Finally, the downstream costs and implications of medication errors avoided as a result of ADDs should be investigated and used to inform a more robust economic analysis.

\section{References}

1. Kohn LT, Corrigan JM, Donaldson MS, editors. To err is human: building a safer health system. Washington (DC): National Academy Press, Institute of Medicine, Committee on Quality of Health Care in America; 2000 [cited 2013 Jun 18]. Available from: www.nap.edu/openbook. php?isbn $=0309068371$

2. Hohl CM, Nosyk B, Kuramoto L, Zed PJ, Brubacher JR, Abu-Laban RB, et al. Outcomes of emergency department patients presenting with adverse drug events. Ann Emerg Med. 2011;58(3):270-9.e4.

3. Hospital pharmacy in Canada 2011/2012 report. Eli Lilly; 2013 [cited 2014 Mar 31]. Available from: www.lillyhospitalsurvey.ca/hpc2/content/ 2012_report/FULL-2012.pdf

4. Pedersen CA, Schneider PJ, Scheckelhoff DJ. ASHP national survey of pharmacy practice in hospital settings: dispensing and administration2011. Am J Health Syst Pharm. 2012;69(9):768-85.

5. Automated dispensing cabinets in the Canadian environment. ISMP 
Canada Saf Bull. 2007;7(3):1-3. Also available from: www.ismpcanada.org/download/safetyBulletins/ISMPCSB2007-03ADCs.pdf

6. Perras C, Jacobs P, Boucher M. Technologies to reduce errors in dispensing and administration of medication in hospitals: clinical and economic analyses. Ottawa (ON): Canadian Agency for Drugs and Technologies in Health; 2009.

7. Lee L, Wellman G, Birdwell S, Sherrin T. Use of an automated medication storage and distribution system. Am J Hosp Pharm. 1992; 49(4):851-5.

8. Borel J, Rascati K. Effect of an automated, nursing unit-based drugdispensing device on medication errors. Am J Health Syst Pharm. 1995; 52(17):1875-9.

9. Ray M, Aldrich L, Lew P. Experience with an automated point-of-use unit-dose drug distribution system. Hosp Pharm. 1995;30(1):18,20-3,27-30.

10. Schwarz H, Brodowy B. Implementation and evaluation of an automated dispensing system. Am J Health Syst Pharm. 1995;52(8):823-8.

11. Guerrero RM, Nickman NA, Jorgenson JA. Work activities before and after implementation of an automated dispensing system. Am J Health Syst Pharm. 1996;53(5):548-54.

12. Wise L, Bostrom J, Crosier J, White S, Caldwell R. Cost-benefit analysis of an automated medication system. Nurs Econ. 1996;14(4):224-31.

13. Shirley K. Effect of an automated dispensing system on medication administration time. Am J Health Syst Pharm. 1999;56(15):1542-5.

14. Chapuis C, Roustit M, Bal G, Schwebel C, Pansu P, David-Tchouda S, et al. Automated drug dispensing system reduces medication errors in an intensive care setting. Crit Care Med. 2010;38(12):2275-81.

15. Wickström G, Bendix T. The "Hawthorne effect"- what did the original Hawthorne studies actually show? Scand J Work Environ Health. 2000;26(4):363-7.

16. Ledlow G, Stephens J, Fowler H. Sticker shock: an exploration of supply charge capture outcomes. Hosp Top. 2011;89(1):1-8.
17. American Society of Health-System Pharmacists. ASHP guidelines on the safe use of automated medication storage and distribution devices. Am J Health Syst Pharm. 1998;55(13):1403-7.

Nicole W Tsao, BSc, MSc(Pharm), is with the Collaboration for Outcomes Research and Evaluation, Faculty of Pharmaceutical Sciences, The University of British Columbia, Vancouver, British Columbia. She was one of the two co-leads on this project.

Clifford Lo, BSc(Pharm), MHA, PharmD, BCPS, is with the Fraser Health Authority, Surrey, British Columbia. He was one of the two co-leads on this project.

Michele Babich, BSc(Pharm), MHSC, CHE, is with the Fraser Health Authority, Surrey, British Columbia.

Kieran Shah is a student in the Faculty of Pharmaceutical Sciences, The University of British Columbia, Vancouver, British Columbia.

Nick J Bansback, BSc, MSc, PhD, is with the Centre for Health Evaluation and Outcomes Sciences, Faculty of Medicine, The University of British Columbia, Vancouver, British Columbia.

Competing interests: None declared.

\section{Address correspondence to:}

Dr Clifford Lo

Surrey Memorial Hospital

Fraser Health Authority

13750 96th Avenue

Surrey BC V3V 1 Z2

e-mail: clifford.lo@fraserhealth.ca

\section{Appendix 1. Search Strategy for Ovid MEDLINE In-Process and Other Non-Indexed Citations and Ovid MEDLINE, 1946 to present}

\begin{tabular}{llc} 
Search & Search Term & $\begin{array}{c}\text { No. of Items } \\
\text { Returned }\end{array}$ \\
\cline { 2 - 3 } 1 & automated dispensing device.mp. & 3 \\
\hline 2 & automated dispensing cabinet.mp. & 12 \\
\hline 3 & automated dispensing machine.mp. & 3 \\
\hline 4 & drug distribution system.mp. & 132 \\
\hline 5 & (Pyxis or Medstation).mp. & 24 \\
\hline 6 & Omnicell.mp. & 0 \\
\hline 7 & 1 or 2 or 3 or 4 or 5 & 173 \\
\hline 8 & limit 7 to (english language and $\left.\mathrm{yr}={ }^{\prime \prime} 1992-2012^{\prime \prime}\right)$ & 71 \\
\hline
\end{tabular}

